\title{
Prevalence of urinary tract infection in homosexual and heterosexual men
}

\author{
A P R WILSON* S J TOVEY, $\uparrow M$ W ADLER, $\dagger$ AND R N GRÜNEBERG* \\ From the *Department of Clinical Microbiology, University College Hospital, and the †Department of \\ Genitourinary Medicine, Middlesex Hospital, London
}

SUMMARY Homosexual practices might be expected to result in an increase in urinary tract infection in adult men. Midstream urine specimens were collected from 200 homosexual and 205 heterosexual men attending a clinic for sexually transmitted diseases. Three specimens from each group yielded more than $10^{5}$ Escherichia coli per ml. The prevalence of urinary tract infection among homosexuals was therefore similar to that in the heterosexual population.

\section{Introduction}

Urinary tract infection in adult men is not an uncommon occurrence. Pead and Maskell found 223 patients with appreciable bacteriuria among 999 men who consulted their general practitioners with dysuria, frequency of micturition, or loin pain. ${ }^{1}$ The association between sexual intercourse and urinary tract infection in women is well documented, ${ }^{2}$ but similar information for the prevalence of urinary tract infection in homosexual compared with heterosexual men is lacking. Urethral contamination by the potential urinary pathogens that abound in the rectal flora might be expected to result in a higher incidence of urinary tract infection in homosexual men, particularly in those taking an active rather than passive role.

This study was undertaken to assess the prevalence of urinary tract infection in men attending a clinic for sexually transmitted diseases (STDs).

\section{Methods}

Midstream urine specimens were collected from men attending the genitourinary clinic at the Middlesex Hospital between 15 April and 19 May 1985. All attenders not taking antibiotics and not previously tested were included. For the first two weeks of the study urine samples were obtained from homosexual men only, and for the second two weeks from heterosexual men only. Urine samples were

Address for reprints: Dr A P R Wilson, Department of Clinical Microbiology, University College Hospital, Grafton Way, London WCIE 6AU

Accepted for publication 14 November 1985 refrigerated immediately and sent to the laboratory within six hours. The presence of appreciable bacteriuria was assessed by the screening method of Leigh and Williams. ${ }^{3} \mathrm{~A}$ filter paper strip dipped into the urine was pressed on to a cysteine lactose electrolyte deficient (CLED) medium. Urine samples yielding a pure growth after overnight incubation were measured by a surface counting technique on CLED medium, and those with more than $10^{5}$ organisms $/ \mathrm{ml}$ were considered to be appreciable. Sensitivity to antimicrobials was assessed by a modified Stokes method. ${ }^{4}$

\section{Results}

We obtained urine samples from 405 men, of whom 205 were heterosexual (average age 31 (range 20 to 70 ) years) and 200 were homosexual (average age 32

TABLE Antibiotic sensitivities, by disc method, of isolates of Escherichia coli from urine samples of three homosexual and three heterosexual men

\begin{tabular}{|c|c|c|c|c|c|c|}
\hline \multirow{3}{*}{$\frac{\text { Antibiotic }}{\text { Acrosoxacin }}$} & \multicolumn{6}{|c|}{ Sensitivities of strains isolated from: } \\
\hline & \multicolumn{3}{|c|}{ Homosexual men } & \multicolumn{3}{|c|}{ Heterosexual men } \\
\hline & S & $\mathbf{S}$ & $\mathbf{S}$ & $\mathbf{S}$ & $\mathbf{S}$ & $\mathbf{S}$ \\
\hline Amoxycillin & $\mathbf{R}$ & $\mathbf{S}$ & $\mathbf{R}$ & $\mathbf{R}$ & $\mathbf{R}$ & $\mathbf{R}$ \\
\hline Cephaloridine & $\mathbf{R}$ & $\mathbf{S}$ & $\mathbf{R}$ & $\mathbf{R}$ & $\mathbf{R}$ & $\mathbf{M}$ \\
\hline Ciprofloxacin & $\mathbf{S}$ & $\mathrm{S}$ & $\mathbf{S}$ & S & $\mathrm{S}$ & $\mathrm{S}$ \\
\hline $\begin{array}{l}\text { Colistin } \\
\text { sulphamethate }\end{array}$ & $\mathbf{S}$ & $\mathbf{S}$ & $\mathbf{S}$ & $\mathbf{S}$ & $\mathbf{S}$ & $\mathrm{S}$ \\
\hline Gentamicin & $\mathbf{S}$ & $\mathbf{S}$ & $\mathbf{S}$ & $\mathrm{S}$ & $\mathbf{S}$ & $\mathrm{S}$ \\
\hline Nalidixic acid & $\mathrm{S}$ & $\mathrm{S}$ & $\mathbf{S}$ & $\vec{S}$ & $\mathbf{S}$ & $\mathbf{S}$ \\
\hline Nitrofurantoin & $\mathbf{S}$ & $\mathbf{S}$ & $\mathbf{S}$ & $\mathbf{S}$ & $\mathbf{S}$ & $\mathbf{S}$ \\
\hline Norfloxacin & $\mathbf{S}$ & $\mathbf{S}$ & $\mathbf{S}$ & $\mathbf{S}$ & $\mathbf{S}$ & $\mathbf{S}$ \\
\hline Sulphonamide & $\mathbf{R}$ & $\mathbf{S}$ & $\mathbf{R}$ & $\mathbf{R}$ & $\mathbf{S}$ & $\mathbf{R}$ \\
\hline Tetracycline & $\mathbf{R}$ & $\mathbf{S}$ & $\mathbf{S}$ & $\mathbf{R}$ & $\mathbf{S}$ & $\mathbf{R}$ \\
\hline Trimethoprim & $\mathbf{R}$ & $\mathbf{S}$ & $\mathbf{S}$ & $\mathbf{S}$ & $\mathbf{S}$ & $\mathbf{R}$ \\
\hline
\end{tabular}

$\mathrm{R}=$ resistant, $\mathrm{S}=$ sensitive, $\mathrm{M}=$ moderately sensitive. 
(range 20 to 59) years). Three positive cultures were found in each group, all yielding Escherichia coli at more than $105 / \mathrm{ml}$. The table shows the antibiotic sensitivities of all six strains. All three homosexual patients complained of occasional dysuria. Two took both active and passive roles, each with a regular partner, but the third took an active role only. The latter patient also gave a ten day history of swollen testicles. The three heterosexual patients complained of dysuria or pruritus. One man had been treated twice previously for recurrent urinary tract infection with $E$ coli. Mixed growth of doubtful importance was noted in one specimen from a homosexual patient and in three from heterosexual patients.

\section{Discussion}

There was no difference in the prevalence of urinary tract infection in homosexual and heterosexual men in this study, which was $1.5 \%$ in both groups on the basis of single urine specimens. Kass found appreciable bacteriuria in $5 \%$ of male patients attending a general medical clinic. ${ }^{5}$ Single samples may be associated with a false positive rate of $20 \%$, and two consecutive samples of urine are a more reliable indicator of appreciable urinary tract infection. ${ }^{5}$ Second specimens could not be obtained from the patients in our study as either they did not return for follow up or they were treated with antibiotics at their first attendance. A mixed growth was present in a further $1 \%$ of the samples. The predominance of $E$ coli confirms previous work on urinary tract infection in adult men and contrasts with that in boys, in whom Proteus spp are the major pathogens ${ }^{1}$. Contrary to expectation, homosexual practices do not predispose to urinary tract infection.

One of us (APRW) is employed as a research registrar funded by Merrell Dow Pharmaceuticals.

\section{References}

1. Pead L, Maskell R. Urinary tract infection in adult men.J Infect 1981;3:71-8.

2. Kunin CM, McCormack RC. An epidemiologic study of bacteriuria and blood pressure among nuns and working women. $N$ Engl J Med 1968;278:635-42.

3. Leigh DA, Williams JD. Method for the detection of significant bacteriuria in large groups of patients. J Clin Path 1964;17:498503.

4. Stokes EJ, Ridgway GL. Clinical bacteriology. 5th ed. London: Edward Arnold, 1980:209-21.

5. Kass EH. Pyelonephritis and bacteriuria. A major problem in preventative medicine. Ann Intern Med 1962;56:46-53. 